\title{
A DRAMATIZAÇÃO DO MITO
}

Diego Lanza*

RESUMO Costuma-se dizer que os espectadores das tragédias já conheciam os mitos nelas dramatizados. Mas o que conheciam realmente dessas histórias? As relações entre mito e tragédia são tão lineares assim? $O$ presente artigo procura justamente questionar essa linearidade, evidenciando o tipo de adaptações, cortes e escolhas sofrido pelo material mítico na sua passagem à cena. A tragédia restringe-se a certos segmentos do relato mítico, aqueles que o poeta julga ser o momento em que se concentra o significado de todo o fato. A memória de acontecimentos extraordinários e de grandes empresas transforma-se, então, em memória de fortes emoções, $o$ que condiciona fortemente nossa visão dos mitos gregos.

Palavras-chave: tragédia, mito, memória, ação humana, emoção.

ABSTRACT It is commonly said that spectators of tragedies already knew the myths enacted in them. But what did they really know of these stories? Are the relations between myth and tragedy that linear? The presente article aims precisely at questioning this linearity, by showing the kind of claims, cuts and choices suffered by the mythical material on its way to the scene. Tragedy is restricted to certain segments of the mythical tale, those the poet thinks to be moments in which is concentrated the meaning of the whole fact. The memory of extraordinary events and of great endeavors becomes then the memory of strong emotions, which strongly determines our view of Greeks myths.

Key words: tragedy, myth, memory, human action, emotion.

* Professor de Literatura Grega da Università degli Studi di Pavia, Itália. Texto recebido em abril e aprovado em maio de 2003. 
"Feliz é a tragédia, dentre todas as poesias, se é verdade, antes de tudo, que os relatos já são conhecidos dos espectadores mesmo antes de que alguém fale, de modo que o poeta deve só lembrá-los. Quando eu falar de Édipo, eles já sabem tudo: o pai, Laio, a mãe, Jocasta, quem são as filhas e os filhos, o que ele sofrerá, o que fez..."

Mas as relações entre mito e tragédia são realmente tão lineares, como nos sugere o poeta cômico? Bruno Snell fez do encontro do mito com a tragédia um momento muito importante da história do espírito:

“A tragédia não se atém rigidamente aos acontecimentos do mito, não os considera uma realidade histórica como faz a épica, mas procura os motivos dos acontecimentos na ação humana e, assim, negligencia o fato puro. [...] Foi Ésquilo o primeiro a conceber a ação humana como resultado de um processo interior e desse processo notou (como costuma acontecer nas descobertas de caráter fundamental) justamente seu ponto essencial; nas situações trágicas ele procura darnos uma representação o quanto possível clara da ação humana em sua essência" ${ }^{2}$.

Essa pasagem pertence ao ensaio Mito e realidade na tragédia grega, escrito em 1944 e que lemos na Entdeckung des Geistes; mas já antes, na sua pesquisa Ésquilo e a ação dramática —publicada em 1928, mas que, como Habilitationschrift, remonta a 1925- Snell escrevia:

"A novidade, a síntese se tem quando surge a consciência de ter diante de si a ação, de se encontrar no momento da decisão. E essa síntese se exprime em sua forma própria, no drama. Em Ésquilo o problema tì dráso; (“que devo fazer?") é posto no ápice de sua última e máxima tragédia com toda a angústia de um homem encurralado; e com isso o agir é compreendido em seu ponto mais profundo e problemático. Somente com esse olhar no próprio futuro o homem capta o seu $\mathrm{Eu}$ como interioridade real, não como simples Ele ou Tu, ao modo do épos ou da lírica"3.

Aqui o eco de Hegel e das outras grandes vozes do debate romântico sobre os gêneros poéticos ainda ressoa com nitidez, e é justamente essa robusta e consciente nervura teórica o que confere fascínio à interpretação de Snell e permite sua afirmação, pelo menos no âmbito da cultura alemã, pois fora da Alemanha Snell foi geralmente lido prescindindo do quadro de suas referências culturais. Quando a Entdeckung foi divulgada ao vasto público

1 ANTÍFANES fr. 189, 1-8 KA (=Ateneu VI 222a-b). As traduções dos autores gregos foram feitas levando em consideração tanto o original grego quanto a interpretação do autor do presente artigo [N.d.T].

2 SNELL, B., Die Entdeckung des Geistes. Studien zur Entstehung des europäischen Denkens bei den Griechen, Hamburg 1933; trad. it., La cultura greca e le origini del pensiero europeo, Torino 1963, p. 159;, trad. port. de Artur Morão, A descoberta do espírito, Edições 70, Lisboa 1992.

3 SNELL, B., «Aischylos und das Handeln im Drama», Leipzig 1928, Philol. Supplb. 20, 1, p.32 s.; trad. it., Eschilo e l'azione drammatica, Milano 1969, p. 35. 
dos filólogos europeus com a tradução em inglês, sua idéia de tragédia foi pormenorizadamente discutida ${ }^{4}$.

Mas é no início dos anos Setenta que Jean Pierre Vernant interroga-se saudavelmente sobre o sentido das distinções categoriais usadas quer por Snell quer — principalmente- por seus críticos:

"Decisão sem escolha, responsabilidade independente das intenções, tais seriam dizem-nos - as formas da vontade nos Gregos. Todo o problema é o de saber o que os próprios Gregos entendiam por escolha e falta de escolha, por responsabilidade com ou sem intenção. Nem mais nem menos do que a de vontade, nossas noções de escolha e de livre escolha, de responsabilidade e de intenção não são diretamente aplicáveis à mentalidade antiga, onde elas apresentam-se com valores e segundo uma configuração que corre o risco de desconcertar uma mente moderna".

E ainda:

"A vontade não é uma categoria simples; como suas dimensões, suas implicações são múltiplas"s.

Às justificadas dúvidas categoriais de Vernant pode-se, talvez, acrescentar alguma dúvida sobre o próprio significado da expressão que, para Snell, é exemplar para a consciência de uma livre escolha do herói trágico: tì dráso; (“que devo fazer?"). É Orestes quem a pronuncia, abrindo a breve esticomítia, que preludia ao matricídio:

“Pílades, que devo fazer? Ter pudor (aidesthô) de matar minha mãe?" (Cho. 899).

Pílades replica imediatamente —e é a sua única fala de toda a tragédia— admoestando-o para não se opor à vontade dos deuses.

Mas é realmente uma pergunta a de Orestes? Se considerarmos as outras aparições de tì dráso; nas tragédias que é possível ler, podemos ficar com uma impressão diferente. As aparições não são poucas: podemos contar quase vinte, e em todas é evidente não a dúvida da escolha entre duas ações a empreender, e sim a frustração de uma situação sem saída, de aporía, de amekhanía. A construção prevalente (8 vezes) é, com efeito, oímoi tì dráso;. Uma vez (Tro. 793) está associado ao homérico tí pátho; ("que farei? que aconte-

4 Em 1953 aparece Discovery of Mind; na Itália a tradução da primeira edição do livro aparece com um título - pensava-se - mais apetecível aos leitores italianos, principalmente ao público da editora. Snell resulta, todavia, bem mais importante na Itália do que em outros países, como demonstram as traduções de outras três obras suas.

5 Citado em francês no texto [N.d.T]. VERNANT, J.-P., «Ébauches de la volonté dans la tragédie grecque» [1972], em Mythe et tragédie en Grèce ancienne, Paris 1973, p. 41 s. (citação, p. 48 e 47 respectivamente). 
cerá comigo?"), uma outra vez (Or. 309) não é menos significativo: gynè tì dráso; ("mulher que sou, que posso fazer?") 6 . Snell, no entanto, não estava errado em reconhecer nessas palavras uma expressão tipicamente trágica. Confirma-o Aristófanes, que a usa, pelo que podemos ler, pelo menos cinco vezes e sempre com um tom paratragódico, como mostra a composição do verso, senão a própria situação cênica: Diceópolis que macaqueia Eurípides (Ach. 466) ou o próprio Eurípides às voltas com o guardião (Thesm. 1128) ${ }^{7}$.

Ao que parece, então, a expressão de Ésquilo torna-se própria dos momentos de maior tensão trágica, marcando não a possibilidade de uma escolha e logo a liberdade de uma decisão autônoma, mas antes o desespero da impotência. É assim para o Orestes das Coéforas? Eu creio que sim. Creio que Snell, mas não só ele, tenha em alguma medida deixado de considerar que terrífico desgosto devesse provocar nos espectadores a ostentação de um propósito matricida. Matar a própria mãe, ainda que culpada, é uma enormidade e, mesmo podendo encontrar em seguida uma espécie de explicação teológica (Apolo nas Eumênides), o ato em si, em sua verbalização cênica que anuncia a execução atrás da cena, não pode não aparecer como horrendo e repugnante. Orestes é, assim, obrigado a isso e enuncia a própria impotência diante daquela que é uma violação irremediável da aidós.

Não é casual que a cena seja longamente preparada por uma série de sugestões simbólicas. Clitemnestra executa o gesto materno supremo de mostrar ao filho o seio que o amamentou; o gesto remete certamente ao de Hécuba, descrito por Homero:

"Abriu a roupa e com a outra mão levantou o seio e, derramando lágrimas, disse palavras certeiras: "Heitor, filho meu, tem respeito disto e tem piedade de mim, se um dia te ofereci o seio dissipador de afãs" (Il. 22, 79-82).

Clitemnestra é sim mãe, mas mãe de monstros. É ela mesma que sonha:

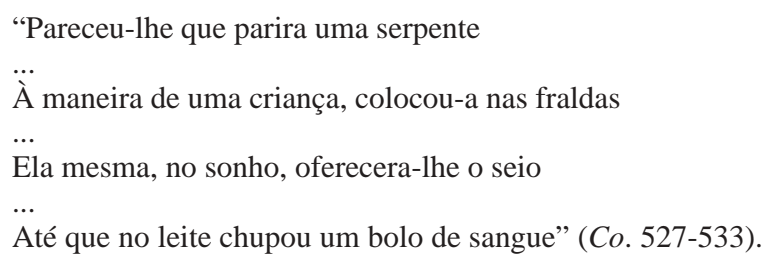

6 O único contexto em que a pergunta dirigida pela personagem a si mesma coloca um efetivo dilema é o de Hec. 737: Hécuba pergunta-se se deve jogar-se aos joelhos de Agamémnon ou sofrer em silêncio. Os outros lugares são: ÉSQUILO, Sept. 1057; SÓFOCLES, Ai. 809, 920, 1024, Phil. 969, 1063, Oed. Col. 1254; EURÍPIDES, Alc. 880, Med. 1376, Heracl. 419, 737, H. F. 1157, Hec. 419, Tro. 793, Phoen. 734, 1277, 1310, 1615, Or. 1610.

7 Cf. também Nu. 844, Pa. 1252 e Eccl. 358. 
A onírica maternidade monstruosa de Clitemnestra é então indicada justamente pelo seio que ela oferece à serpente parida e pelo sangue que daí nasce. Orestes é profeta fácil:

"Eu suplico então a esta terra e ao túmulo paterno que esse sonho seja levado a cabo por mim. Eu discirno-o de maneira aderente [à verdade]: se a serpente, como uma criança, saiu do mesmo lugar de onde eu saí, foi dotada de fraldas, pôs na boca o seio que foi instrumento de minha nutrição, e misturou com um bolo de sangue o seu caro leite e ela, amedrontada, gemeu por tal sofrimento, já que nutriu o monstro assustador, deve morrer com violência, e sou eu [...] que vou matá-la, como narra o sonho" (Co. 540-550).

Não mãe ou mãe de monstros, Clitemnestra é, ela mesma, um monstro. A imagem aparece duas vezes:

“Ó, Zeus, Zeus, —invoca Orestes— - sê testemunha destes fatos: olha a estirpe órfã da águia pai falecido nas dobras e nas contorções de uma tremenda víbora" (Co. 246-9).

Na cena de Ésquilo do matricídio, do matricídio verbal na cena que precede o real atrás da cena, há, assim, um jogo intenso entre os sinais tradicionais da maternidade e os da monstruosidade que, enquanto aumenta a tensão dramática, tempera, talvez, a repugnância pelo ato que o deus impôs a Orestes e contribui a torná-lo de algum modo plausível.

É óbvio que a imediatez da cena requer critérios de aceitabilidade diferentes dos de uma simples narração; as estratégias da dramatização são, assim, diferentes, ao repropor as narrações tradicionais.

Uma diferença de grande relevo está, por exemplo, na representação das relações entre o homem e a divindade. Na narração épica deuses e heróis dialogam entre si, às vezes até mesmo se ameaçam e caçoam uns dos outros reciprocamente. É o caso de Diomedes, que não só fere Afrodite, mas lhe dirige abertamente palavras de escárnio:

"Vai embora, filha de Zeus, do embate da guerra. Não te basta seduzir mulheres imbeles? Mas, se freqüentares a guerra, penso que tu temerás a guerra mesmo ouvindo falar [dela] de longe" (Il. V 348-451).

Helena também alterca com Afrodite antes de ser obrigada a ceder, e o tom do diálogo não se apresenta diferente de uma desavença entre duas mulheres:

“«Desgraçada, por que me enganas e me seduzes? Ainda me levarás mais longe nas populosas cidades da Frígia ou da amável Meônia, se aí também te for caro algum dos homens mortais?» 
A ela irada respondeu a resplendente Afrodite: «Não me provoques, miserável, a que eu, irada, te deixe e, quanto até aqui te amei, tanto te odeie e desencadeie entre ambos, Troianos e Dânaos, ódios lutuosos, e tu morrerás de sina ruim»" (Il. III 399402; 413-6).

$\mathrm{O}$ aedo pode permitir-se isso porque os acontecimentos que ele conta pertencem a um outro tempo, a um tempo remoto. O poeta épico frisa com ênfase a distância que separa o herói, o homem do passado longínquo, do homem de seu tempo:

"E ele, o filho de Tideu, pegou uma pedra, grande empresa, que nem dois homens, como agora são os mortais, carregariam, mas que ele, até mesmo sozinho, facilmente sacudia" (Il. V 302-4).

O confronto com o presente serve ao aedo para sugerir a imagem dos heróis, extraordinários e irrepetíveis. Mas os heróis, por sua vez, quando evocam o próprio passado, não se comportam de maneira diversa do aedo. $\mathrm{O}$ velho Nestor em Tróia relembra os tempos de sua juventude distante e os guerreiros com que combatera, guerreiros em luta com os centauros sobre os quais no final triunfaram:

"A eles então eu me uni, vindo de Pilo, de uma terra distante; foram eles que me chamaram e eu combati por minha conta, mas com eles nenhum dos mortais que hoje estão sobre a terra combateria" (Il. I 269-272).

O efeito de duplicação decerto não é proposital; é apenas um sinal da necessidade que o aedo tem de pensar — e fazer suas próprias personagens pensar- o tempo em termos de extraordinariedade irrecuperável.

A representação dramática opera de maneira contrária porque deve sugerir a ilusão de que os acontecimentos se desenrolam diante do público e que as personagens, deuses e heróis, agem no presente. Muitas vezes essa contemporaneidade fictícia é, por assim dizer, reiterada até mesmo verbalmente, como que a indicar que o espectador é chamado a assistir justamente ao momento crucial do inteiro acontecimento, no dia em que a história do herói chega ao seu ponto determinante. "Nesse dia...", "num dia só..." são expressões que podemos encontrar nas palavras de quem, deus ou adivinho, já conhece os acontecimentos e adverte o protagonista ${ }^{8}$.

A teofania trágica também tem regras próprias, muito diferentes das da narração épica. O deus não se mistura com os heróis, e os heróis são representados nos limites da própria humanidade, não porque eles e suas vicissitu- 
des sejam a reprodução cênica da vida cotidiana, mas porque as relações com o deus aparecem rigorosamente disciplinadas. Eles ouvem os deuses e thes obedecem sem discutir; e os deuses, quando aparecem, permanecem em um plano visualmente bem distinto, a saber, na mekhané ou no theologeîon.

Sabemos que já a épica opera processos de ressemantização. Muitas vezes os fatos que o aedo deve contar ou as figuras que entram em seus relatos não são facilmente compreensíveis para o público e para ele mesmo, de modo que devem ser replasmados segundo diferentes critérios de credibilidade, que interpretem ou substituam crenças e rituais já em desuso: Tersites, Dólon, o próprio Ulisses são um claro testemunho disso ${ }^{9}$.

Os mûthoi, ou seja, as histórias tradicionais, são, de resto, continuamente revisitados, repropostos em circunstâncias e com modalidades de execução diferentes, procurando toda vez torná-los compreensíveis segundo os diferentes códigos expressivos, procurando oferecer deles uma interpretação, isto é, uma justificação.

Mas por que os mitos devem ser explicados? Ou, para colocar a pergunta mais claramente: por que histórias que são às vezes de difícil decifração devem ser retomadas e recontadas? Não é aqui minha tarefa, nem está em minhas possibilidades, enfrentar de maneira satisfatória o conjunto de questões teóricas que comporta a simples pergunta "o que é um mito?" ou diversamente formulada, “o que é o mito?". São questões que, como recentemente Cristiano Grottanelli ${ }^{10}$ mostrou bem, remetem inevitavelmente a reflexões e pontos bem mais gerais: tem sentido contrapor mito a razão, mito a história, mito a linguagem etc.? Deixo, então, de lado tais perguntas não porque não nos digam respeito, mas porque penso que seja possível dizer algumas coisas mais circunscritas e, entretanto, historicamente fundadas, sem dever previamente resolvê-las. Está claro, por outro lado, que qualquer pessoa que se ocupe de poesia grega já fez, ainda que de maneira inconsciente, opções que condicionam teoricamente seu próprio operar. Não é difícil, de resto, entender como todas essas questões pressupõem como crucial o antigo problema da origem do mito: como ele nasce, quando, por quê? Eu preferiria, pelo menos nisso, o ponto de vista de Walter Burkert: não interessa como o mito nasce, interessa antes como e por que é guardado e trasmitido. Burkert sugere naturalmente uma primeira resposta que pode, talvez, parecer um tanto quanto genérica, mas que vale a pena lembrar:

9 Remeto aqui, inclusive para a bibliografia, ao exame crítico de BERTOLINI, F., «Società di trasmissione orale: mito e folclore», em CAMBIANO, G.- CANFORA, L. - LANZA D. (a cura $d \imath$ ), Lo spazio letterario della Grecia antica, I 1, Roma 1992, p. 47 s.

10 GROTTANELLI, C., «Problemi del mito alla fine del Novecento», Quaderni di Storia 46 (1997), p. 183. 
"O mito é uma narração tradicional com uma referência secundária, parcial, a algo que tem importância coletiva"

Mais recentemente, Jan Assmann reiterou que na memória social de um grupo se guarda o que serve para garantir seu sentido de identidade ${ }^{12}$. Muitas das observações de Assmann sobre o mundo grego não me parecem felizes, inclusive porque a sua visão da Grécia é inevitavelmente mediada por um determinado milieu filológico, o alemão, com o qual a sua pesquisa teórica na verdade não tem muito a ver. Mas isso não é importante. Acredito que seja, ao contrário, muito útil o que suas páginas sugerem implícita ou explicitamente, a saber, que a investigação sobre o mito — seja qual for a definição que preferimos dar do mito- deva ser revista no interior de uma consideração mais ampla e geral sobre a memória cultural de uma sociedade.

Isso não significa que os relatos transmitidos fossem imediatamente perspícuos, mas dá conta da preocupação de torná-los tais por parte de quem —o poeta, em primeiro lugar-é delegado socialmente à sua conservação e transmissão. Mas o que implica essa conservação? Estou ciente do fato de a pergunta poder arrastar-nos em uma controvérsia abusada: os Gregos acreditavam ou não acreditavam em seus mûthoi, acreditavam ou não acreditavam em seus deuses e em seus heróis? O perigo pode, todavia, ser evitado: memória social não é, com efeito, fé em acontecimentos ocorridos, consciência histórica como nós comumente entendemos, mas partilha lembranças significativas, continuidade com um passado em que se reconhece o sentido forte da própria identidade. É a confiança no fato de o passado, tal como é lembrado, ser a garantia suprema do que somos, ou melhor, do achamos que somos.

Se o mito é, então, parte da memória social, está claro que a sua dramatização, isto é, o repropô-lo não como passado remoto, mas como presente, ainda que fictício, pode colocar algum problema. E, de fato, o mito na tragédia aparece de modos e segundo lógicas diferentes.

Devemos considerar, antes de tudo, a história que é tomada como matéria da dramatização. Ou melhor, o segmento de história, já que a tragédia limita-se sempre a dramatizar um pedaço de um relato mítico, aquele que o poeta julga ser seu ponto crucial, o momento em que o próprio significado de todo o acontecimento parece concentrar-se: o assassinato de Agamémnon, a descoberta de si mesmo feita por Édipo, a loucura de Héracles, o revelar-se do eídolon de Helena etc. Todo segmento dramatizado, por outro lado, pres-

11 BURKERT, W., Structure and History in Greek Mythology and Ritual, Berkeley 1979, p.23; trad. it., Mito e rituale in Grecia, Laterza Bari 1987, p. 38.

12 ASSMANN, J., Das kulturelle Gedächtnis. Schrift, Erinnerung und politische Identität in frühen Hochkulturen, München 1992; trad. it., La memoria culturale. Scrittura, ricordo e identità politica nelle grandi civiltà antiche, Einaudi, Torino 1997. 
supõe um antes e um depois, e não é, como pretende Aristóteles, um hólon, um todo autônomo que basta a si mesmo. Pressupõe-se que o que precede e o que sucede sejam, sim, já conhecidos do público, mas isso não exime o poeta de relembrá-los, às vezes com muita insistência, na tragédia. Os coros de Agamémnon reconstróem, pode-se dizer, a inteira saga dos descendentes de Tântalo, os intensos diálogos de Édipo Rei recompõem pedaço por pedaço o complicado mosaico de uma história desconhecida do protagonista, e em Ifigênia em Táuris, em ocasiões dramáticas diferentes, são evocados todos os reveses da estirpe de Tântalo e Pélops até a futura purificação de Orestes.

Trata-se de simples recapitulações informativas dos acontecimentos? Não parece: o ir além dos limites da ação cênica faz parte, ele mesmo, do ritmo dramático; torna-se, ele mesmo, vetor emotivo. E assim como há a recuperação do passado, há também o anúncio do futuro posto na boca de deuses e adivinhos. O ingresso das Erínias apaziguadas na próspera vida da Ática, a volta de Filoctetes entre os homens, a metamorfose de Hécuba em cadela são todos prolongações, emotivamente necessárias, do que diretamente se passa na cena.

O mito representado pode expandir-se não apenas no que antecede e no que sucede. Pode-se ter às vezes aquilo que poderíamos definir como uma expansão tangencial, ou seja, quando, no curso da ação dramática, é feita alusão a acontecimentos que não pertencem nem ao que antecede nem ao que sucede à ação representada, mas cuja memória está tradicionalmente ligada a uma das personagens presentes em cena. Trata-se, por exemplo, das remissões à juventude do velho Peleu em Andrômaca, da estadia de Egeu em Trezene em Medéia e, naturalmente, da história completa das peregrinações de Io evocada por Prometeu.

Há, ademais, uma outra possibilidade de lembrar ou evocar relatos que não têm diretamente a ver com a ação dramática nem com nenhuma de suas personagens. É uma evocação que se pode definir como analógica: um mito totalmente diferente é evocado para marcar a situação ou o estado em que se encontra o herói da tragédia. É o caso do mito de Níobe, evocado por Antígona antes de desaparecer da cena e da vida:

"Ouvi como muito miseravelmente morreu no pico do Sípilo a estrangeira da Frígia, a filha de Tântalo, que, como hera tenaz, domou o rochoso arvoredo; e a ela, consumida pela chuva - como os homens dizem - nunca a neve abandona, e dos cílios sempre lacrimosos lhe banha os lados. A mim, que sou em tudo semelhante a ela, me abate o demônio" (Sófocles, Ant. 822-832).

É o caso dos mitos de Dânae, de Licurgo e dos filhos de Fineu, relembrados pelo coro logo depois do desaparecimento de Antígona: 
"O corpo de Dânae também sofreu por trocar a luz do céu por um aposento de bronze, e, subtraída aos olhares, foi encerrada em um tálamo sepulcral. Não obstante, era de alta linhagem, ó filha, e guardava em si o sêmen de Zeus, chuva dourada. Mas é tremenda a potência do destino; nem riquezas, nem armas, nem fortaleza, nem naus escuras batidas pelas ondas podem dela proteger.

Foi subjugado o iracundo filho de Driante, o rei dos Edônios, pela sua ultrajante cólera, por parte de Dioniso, amarrado na prisão de pedra; agora a sua tremenda loucura e a sua força florescente vão minguando; assim ele conheceu o deus, ao provocá-lo, louco, com palavras de ultraje" (Sófocles, Ant. 944-961).

São os mitos de Calisto e de Cós que Helena evoca na tragédia que lhe é dedicada:

"Ó virgem, feliz uma vez na Arcádia, Calisto, que com membros quadrúpedes subiste no leito de Zeus, quão mais recebeste do destino que minha mãe; com forma de fera vilosa - figura de leoa de olho resplendente — te livraste das angústias da dor. Tu que também um dia Ártemis tirou do coro, cerva de chifres dourados, a descendente dos Titãs filha de Mérope, por causa de sua beleza. Meu corpo, ao contrário, arruinou, sim, arruinou a fortaleza dos Dárdanos e os Aqueus aniquilados" (Eurípides, Hel. 375-385).

Nesses exemplos, que se poderiam multiplicar ${ }^{13}$, podemos observar que: 1) a evocação é posta em passagens cantadas (solos ou corais) $)^{14}$;

2) muitos desses trechos apresentam dois tipos de marcas distintivas, a saber:

a) marcas que assinalam o valor gnômico do mito evocado em relação à situação da personagem: "a mim, que sou em tudo semelhante a ela" (Sófocles, Ant. 832), "também sofreu..." (944), "meu corpo, ao contrário" (Eurípides, Hel. 383), "assim eu também" (Ésquilo, Suppl. 67), "tu, ao contrário..." (Eurípides, El. 847) etc.;

b) marcas que assinalam o valor secundário do mito evocado, do relato no relato: «ouvi» (Sófocles, Ant. 823), «como os homens dizem» (Sófocles, Ant. 828), «ouço» (Eurípides, Med. 1282), «sei» (Eurípides, El. 838) etc.

Essa dúplice presença de marcas estabelece uma relação de evocação um tanto quanto particular.

Como se vê, estudar a presença do mito na tragédia não é coisas simples. Certamente — repetimos sempre aos nossos alunos - os espectadores anti-

13 Cf. também ÉSQUILO, Suppl. 67 s.; SÓFOCLES, Thrach. 497 s.; EURÍPIDES, Med. 1282 s.; Hipp. 545 s., El. $824 \mathrm{~s}$.

14 A única exceção é o discurso da Ama (Hipp. 450 s.), mas sobre o jogo entre ritual e dramatização nessa tragédia, cf. LONGO, O., «Ippolito e Fedra fra parola e silenzio», em Atti delle giornate di studio su Fedra, A.I.C.C., Torino 1985 , p. 79 s. 
gos já conheciam a história a que estavam para assistir. Mas o que conheciam dessa história? Não podemos saber quais fossem as margens de originalidade do aedo antigo na reelaboração das próprias histórias: como Demódoco cantou o episódio do cavalo a ponto de comover Ulisses, usando que personagens, insistindo em que pormenores? Temos, todavia, testemunho, ainda que indireto, de como os três maiores trágicos desenvolveram algumas mesmas histórias. Eu poderia dar o exemplo, muito conhecido, de Coéforas e das duas Electra, mas correria o risco de ficar preso em uma rede, que as inúmeras investigações críticas modernas tornaram particularmente complicada. Prefiro, por isso, uma outra história, a de Filoctetes.

Ésquilo, Eurípides e Sófocles compuseram, cada um deles, um Filoctetes. Apesar de o de Sófocles ser o único a ter sido conservado, por sorte somos informados por Díon de Prusa dos traços distintivos dos outros dois.

Em Ésquilo o engano de Ulisses funciona: travestido, ele conta a Filoctetes que os Gregos encontram-se em dificuldade pela sua própria morte e a do grande Agamémnon.

Em Eurípides (seu drama é anterior de pelo menos vinte anos ao Filoctetes de Sófocles e se coloca, assim, nos primeiros anos da Guerra do Peloponeso), Filoctetes encontra-se no centro de um grande debate: por um lado, a delegação dos Gregos (o engano de Ulisses é logo descoberto), por outro, os mensageiros troianos. Estes últimos esperam aproveitar da hostilidade que Filoctetes não esconde pelos seus compatriotas, oferecendo-lhe ajuda e hospitalidade, mas inutilmemente. Em Filoctetes acaba prevalecendo o amor pela pátria.

Enfim, Sófocles: Ulisses serve-se do jovem filho de Aquiles, Neoptólemo, que, como Filoctetes, foi vítima de uma injustiça por parte dos chefes dos Gregos. Inicialmente engana Filoctetes, depois se arrepende e lhe revela tudo, prometendo-lhe hospitalidade em sua cidade. Quando os dois estão para partir juntos para a Grécia, aparece ex machina Héracles que ordena a Filoctetes para ir a Tróia e preanuncia a ele e a Neoptólemo a glória comum da conquista da cidade.

Os elementos essenciais da história permanecem os mesmos, mas se falou em variantes míticas. Na realidade, o que muda é apenas a psicologia de Filoctetes, a representação de seus sentimentos, de suas dúvidas, de sua decisão, que é a explicação cada vez considerada mais crível da história representada.

Por conseguinte, é a própria categoria de variante mítica que provavelmente deve ser questionada. Variante, de fato, em relação a quê?

Quando o mito é citado como exemplo gnômico (os casos já citados de Níobe em Antígona e de Calisto em Helena), parece pressuposto que o signi- 
ficado esteja claro. E que outro valor pode ter a vingança de Orestes lembrada como exemplum ao jovem Telêmaco, se não o do dever primário de fidelidade do filho ao próprio pai? Parece que existe então um significado certo de Níobe, ou então o jogo da alusão poética é mais sutil e as palavras de Antígona não evocam uma genérica Níobe, e sim uma figura de Níobe que já apareceu na cena, dramaticamente definida e, por isso, vividamente impressa na memória dos espectadores? Não creio que seja possível responder com certe$\mathrm{za}$, nem oferecer uma resposta que pretenda uma validade universal, mas isso não significa que não tenha sentido colocar a pergunta.

É muito provável que a representação trágica dos mitos tenha contribuído para aquele trabalho de reorganização que a narração épica já empreendera direta e indiretamente: a ordem das diversas gerações é normalmente conservada e, nesse quadro, às vezes se relacionam lugares e personagens antes sem relação entre si. Já foi observado o papel central que nessa nova geografia do mito a Ática assume: ela torna-se o espaço da expiação, da purificação, do apaziguamento, e Teseu, seu rei, a figura do grande conciliador $^{15}$.

Todavia, esse intenso trabalho em cima do mito, para usar a feliz expressão de Hans Blumenberg, não vai em uma única direção. O sistema dos mitos, a mitologia, que se pode extrair das tragédias, é inevitavelmente um sistema imperfeito, não tanto pelo uso das assim chamadas variantes míticas de que já se viu a precariedade definitória, mas por motivos mais intrínsecos, mais ligados à própria natureza da representação trágica. A figura mítica, ao tornar-se personagem de tragédia, fica carregada de significados novos. É o caso, por exemplo, de Antígona, uma personagem que, como poucos outros, permaneceu vivo na memória cultural européia. Antígona ou a fidelidade ao génos, poder-se-ia dizer, seja qual for o significado último da sua conflituosidade. Antígona fiel ao pai, fiel ao irmão, parthénos não destinada às núpcias. Essa figura forte de mulher que não renuncia, a nenhum custo, aos próprios deveres se conserva intacta na passagem de Antígona a Édipo em Colono, e é justamente tal permanência que provavelmente fixa sua imagem exemplar fora de qualquer contexto trágico. Mas para conseguir tal permanência Sófocles foi obrigado a recuperar, com alguma dificuldade, uma coerência narrativa, decerto mais superficial, mas, não obstante, importante para a organização do mito. Antígona, com efeito, corre o risco da ubiqüidade: fiel companheira da andança expiatória do pai até sua morte, após ter pedido em vão para compartilhar seu túmulo, de maneira surpreendente —e são os últimos 
versos de Édipo em Colono - pede para ser mandada de volta a Tebas. Mas Colono era totalmente desconhecida das personagens de Antígona, se Ismene pode afirmar, sem ser desmentida, que Édipo morreu "odiado e desonrado" (apekhthês duskleés te) (Sófocles, Ant. 50). É possível, ou melhor, provável, que a ênfase na figura de Antígona seja própria de Sófocles, e, por isso, é interessante considerar como o poeta fica atento em limitar a incongruência de seu trabalho em cima do mito. Incongruência, de resto, no mais das vezes — com razão- negligenciada, já que é justamente graças a ela que a coerência emotiva da personagem se impõe aos espectadores das duas tragédias.

A sua potência é tal que elimina outras Antígonas, até mesmo a esposa de Hêmon de Eurípides, à qual não está claro se devemos atribuir ou não a rica continuação de reviravoltas que tiramos da narração de Higino, mas da qual não há vestígio em Apolodoro.

É difícil, para nós, ter uma idéia, ainda que aproximativa, das histórias que forneciam assunto às tragédias antigas. Em grande parte perderam-se, e não se pode excluir que um dos critérios seletivos da tradição sucessiva tenha sido a preferência por certos mitos. Tem-se, então, um curioso efeito de difração no conhecimento da mitologia grega: a nós resultam hoje familiares mitos e personagens que no séc. V a.C. não eram mais conhecidos que outros, que em seguida se transformaram em meras curiosidades eruditas. Medéia é para nós, pode-se dizer, paradigmática, enquanto Níobe fica para nós na sombra. Não obstante, a Níobe e a Télefo sabemos que dedicaram tragédias e até mesmo inteiras trilogias todos os três grandes trágicos, sem contar os assimchamados menores.

Não é difícil entender, no entanto, que a reelaboração dramática do mito foi um momento determinante da sua transmissão. A leitura de Apolodoro sugere-nos que algumas tragédias se tenham tornado relativamente cedo a versão, por assim dizer, canônica das histórias nelas dramatizadas: o assassinato de Agamémnon é aquele que vemos em Ésquilo, a inteira história de Édipo é a que resulta da destruição e da reconstrução informativa de Édipo Rei e do mesmo modo no caso de Ifigênia e em outros ainda. Quantas histórias, aliás, tomam emprestada da canonização trágica das mesmas uma estrutura dramática, ou seja, são cadenciadas segundo momentos de forte concentração emotiva, isto é, segundo as cenas que, no jargão teatral, costumam ser definidas 'cenas principais'? Não poucas, se depois alguém pôde ficar persuadido de que os mitos gregos, os principais pelo menos — bem entendido, principais para nós- eram intrinsecamente dramáticos, ou seja, eram de algum modo predispostos pela sua própria natureza a viver na cena.

O mito da memória de extraordinários acontecimentos e de grandes em- 
presas transformou-se, assim, em memória de emoções, emoções fortes, porque fortemente concentradas. Desse modo, perde ele a relevância social que o conservava como espelho de um sentimento de identidade? Essa também é uma pergunta difícil. Como é difícil, para quem considerar -e é uma consideração obrigatória - a iconografia dos mitos também, compreender o quanto a visualização pictórica e plástica se dirige à visualização dramática e o quanto é inspirada por ela. Não para seguir alguns estudiosos em sua precária busca de supostas ilustrações de tragédias, quase fotografias de cena do teatro de Dioniso, mas para perguntar-nos quanto e como a canonização trágica de algumas sequiências míticas tenha podido favorecer uma difusão icônica e tenha determinado ou contribuído para determinar uma espécie de cânon figurativo com forte valor emotivo.

Que, de resto, a emoção fosse um ingrediente cada vez mais importante da memória social, está bem testemunhado pela difusão de um tipo de narração histórica a que os rígidos critérios da historiografia moderna sempre reservaram escassa simpatia e atenção não muito grande. Nesse caso também, entretanto, o problema não é o de avaliar sua qualidade com base em uma anacronística definição de veracidade histórica, e sim o de considerar se ela era uma mera opção literária subjetiva ou se fosse reconhecida como um modo particularmente eficaz de manter a memória do que devia ser socialmente lembrado. Qual era, por outro lado, a lembrança coletiva que os Atenienses do quinto século guardavam de uma experiência fundamental como a batalha de Maratona?

Mas aqui o discurso corre realmente o risco de se dilatar excessivamente e, por isso, é oportuno interrompê-lo. Voltando ao teatro, pode-se perguntar: quais teriam sido os paradedoménoi mûthoi sem a sua dramatização, quanta e qual memória do mito grego poderíamos ter sem a tragédia? 